\title{
Links between Faith and Some Strengths of Character: Religious Commitment Manifestations as a Moderators
}

\author{
Marcin Wnuk \\ Department of Psychology, Adam Mickiewicz University in Poznań, 60-568 Poznań, Poland; \\ marwnu@amu.edu.pl; Tel.: +48-664-934-268
}

check for updates

Citation: Wnuk, Marcin. 2021. Links between Faith and Some Strengths of Character: Religious Commitment Manifestations as a Moderators. Religions 12: 786. https://doi.org/ $10.3390 /$ rel12090786

Academic Editor:

Pninit Russo-Netzer

Received: 28 August 2021

Accepted: 15 September 2021

Published: 18 September 2021

Publisher's Note: MDPI stays neutral with regard to jurisdictional claims in published maps and institutional affiliations.

Copyright: (C) 2021 by the author. Licensee MDPI, Basel, Switzerland. This article is an open access article distributed under the terms and conditions of the Creative Commons Attribution (CC BY) license (https:/ / creativecommons.org/licenses/by/ $4.0 /)$.

\begin{abstract}
Religious commitment is a significant factor for the development of strengths of character. Previous studies have confirmed that for religious people, it is not religious affiliation but religious orientation that has influenced positive outcomes. The purpose of the research was to verify whether religious commitment moderates the relationship between faith and strengths of character in a sample of religious students from Poland. A cross-sectional investigation of 393 Polish students was performed with using following measures: the Santa Clara Strength of Religious Faith Questionnaire (SCSORFQ), the Transgression-Related Interpersonal Motivations (TRIM) scale, the Gratitude Questionnaire (GQ-6), the Purpose in Life Test (PIL) test, the Herth Hope Index (HHI), the Brief Religious Coping Scale (Brief RCOPE), and two one-item tools measuring religious practices such as frequency of prayer and attendance at Mass. The obtained results confirmed the moderating role of prayer, mass attendance, and positive religious coping on faith and meaning in life as well as hope. Additionally, positive religious coping moderated the relationships between faith and gratitude as well as between faith and motivation to avoid transgressors. The research has proven that faith without religious commitment is not a strong enough factor to improve strengths of character, and being a believer but not practicing religion is not sufficient to lead a person to finding meaning in life, having enhanced hope, or being able to forgive.
\end{abstract}

Keywords: faith; religious practices; religious coping; strengths of character; meaning in life; hope; gratitude; forgiveness; moderator variable

\section{Introduction}

In many philosophical traditions and religious systems, some moral virtues are perceived as valuable goals to achieve and as ways to lead a happy and fulfilling life (Dahlsgaard et al. 2005).

In the area of psychology, singular virtues are treated as strengths of character and are part of bigger factors called virtues. According to this conception, there are six virtues, each of which consists of from three to five strengths of character. There are some criteria of character strengths that are recognized such as ubiquity (prevalent across the culture), fulfilment (influencing individual fulfillment), trait-like (referring to individual difference with demonstrable stability), morally valued, and measurable criteria. (Park et al. 2004).

Generally, most research has confirmed the beneficial role of religion in adolescence (Hardy and King 2019; Hardy et al. 2019). Previous studies have confirmed the positive results of strengths of character on subjective well-being (Kor et al. 2019; Park et al. 2004).

There is a lack of research regarding antecedents of character strengths, especially those that have religious roots. Additionally, there is no identified mechanism that determines how religion can facilitate and enhance some virtues. Within positive psychology, some studies have confirmed that religiosity is a source for some strengths of character, such as gratitude (Krause and Hayward 2015; Sharma and Singh 2018; Ahmed 2009; Root et al. 2017), forgiveness (Sharma and Singh 2018; Ahmed 2009; Davis et al. 2012; Tsang et al. 2020), patience (Schnitker et al. 2017; Schnitker and Emmons 2007; Berthold 
and Ruch 2014; Root et al. 2017), and humility (Root et al. 2017; Krause and Hayward 2015). Most of these studies were conducted among individuals affiliated with Christian denominations, but one can find evidence in the literature that this positive relationship is present in representatives of other than Christian denominations, such as Muslims (Ahmed 2009). Among American Muslim youth, religiosity was positively related to kindness, equity, self-regulation, prudence, gratitude, hope, and forgiveness (Ahmed 2009). In van Oudenhoven et al.'s (2012) study, the self-rated importance of 15 strengths of character did not differ among representatives of four groups (Catholic, Protestant, Muslim, nonreligious). Statistically significant differences in some strengths of character were noticed between culturally different countries, such as between Germany and the Spain and between Netherlands and Spain. This means that no religious affiliation but national culture moderate the relationship between religion and strength of character. In Berthold and Ruch's (2014) study, religious affiliation did not have an influence on gratitude, hope, forgiveness, kindness, love, or spirituality. Those involved in private and public religious practices such as prayer and church attendance scored significantly higher on these virtues than nonreligious individuals and individuals affiliated but not practicing religion. Additionally, there were no differences in either of these groups in reference to the intensity of these virtues, which means that it is not religious affiliation but religious involvement that shapes some moral virtues. Believers who do not practice their religion do not benefit from their religious affiliation. A similar effect was confirmed in a more secular cultural context, where the religiosity of religious people did not influence life satisfaction. In religious nations the religiousness of religious individuals is positively associated with subjective well-being, while non-religious people have higher rates of subjective well-being in non-religious nations (Stavrova et al. 2013; Diener et al. 2011). Additionally, religious orientation can moderate the religion-virtues relationship. According to Allport and Ross (1967), there are two religious motivation types: intrinsic and extrinsic. For the believers representing intrinsic religious orientation, religion is the autotelic and central value of their lives. Extrinsically motivated religious people treat religion as an instrumental value serving to achieve non-religious goals. Further development of this conception led to dividing extrinsic religiosity into extrinsic personal and extrinsic social religiosity (Maltby 2002). In a sample of Methodists 60 years old and above from Leeds, England, intrinsic religiosity positively influenced meaning in life; quest religiosity was not related to this existential variable, but extrinsic religiosity impeded finding meaning in life (Francis et al. 2010). In a sample of graduate students at a Protestant-affiliated university, intrinsic religiosity was positively associated with gratitude and forgiveness, but quest religiosity was not correlated with either of these virtues (Sandage and Harden 2011). Watkins et al. (2003) noticed a positive correlation between gratitude and intrinsic religiosity and a negative correlation between gratitude and extrinsic religiosity. Additionally, McCullough et al. (2004) have confirmed the positive association between intrinsic religiosity and self-reports of a daily grateful mood, but extrinsic religiosity was not correlated with this variable.

Results of research have indicated that intrinsically religiously motivated individuals who treat religion as an autotelic and the central value in their axiological structure receive beneficial effects for strength of character. Their faith is an active, not passive, element of their life that enhances their ability to perceive, interpret, and experience reality according to the religious system, and their commitment to religious activity makes it easier for them to deal with every difficult situation. Believers who hold the strong religious faith are convinced that faith is extremely important to them; it is a source of inspiration and comfort, as well as purpose and meaning in life, and also has a big impact on many decisions and is a source of identity (Plante and Boccaccini 1997a).

It is expected that only students whose faith is reflected in religious commitment experience the beneficial effect of strength of character. Religious commitment was defined as a positive emotional and behavioral attitude towards religion reflected in religious practices such as prayer and Mass attendance and positive religious coping. In other words, the strength of students' faith will have a positive impact on their strength of character 
only if their faith positively corresponds with religious practices and the use of positive religious coping to confront stressful situations. Positive religious coping is a way of coping through using positive references to God and religion, for example, through God's love, finding God's support to deal with anger, or focusing on religion to stop worrying about problems (Pargament et al. 2011). The purpose of this study was to describe and explain the mechanism of the positive influence of interactions of faith with religious commitment on the chosen strengths of character, filling the gap in the literature on this subject.

\section{Religiosity and Meaning in Life}

In positive psychology, strength of character termed spirituality consists of meaning in life as a significant part of this construct.

In the literature, among different approaches to meaning in life, the best-known theory of purpose and meaning in life is the conception of Victor Frankl (Auhagen 2000).

In his theory, the most important motivation is the search for meaning (Frankl 2009). Problems with finding meaning and purpose in life can lead to an "existential vacuum" and other symptoms such as feelings of meaninglessness, hopelessness, senselessness, suicidal thoughts, and anhedonia, which Frankl called "noogenic neuroses" (Frankl 1998).

Religion can facilitate finding purpose and meaning and protect against the "existential vacuum" by supplying a positive, coherent, and predictable philosophy of life, which, in turn, serves as a meaning framework through which believers perceive and explain the reality around them, as well as events and owned experiences, as meaningful. Religion can motivate religious people to find meaning even in tragic situations connected with much suffering, such as cancer (Jim et al. 2006; Fletcher 2004). Among three kinds of valuescreative, experiential, and attitudinal — the last is the most important, being the highest manifestation of humanity. This means that in a complex life situation such as a fatal disease where the individual is no longer able to create or experience, he can nevertheless still find meaning and purpose in his life, suffering with dignity (Frankl 1998). According to recent research, the positive correlation between religiosity and meaning in life seems to be universal, being independent of research samples and measures used as religiosity indicators; for example, positive correlates of purpose and meaning in life were attitude toward Christianity (French and Joseph 1999), intrinsic religiosity (Ardelt 2003; Ardelt and Koenig 2006), spiritual experiences (Wnuk and Marcinkowski 2014), and strength of religious faith (Plante et al. 2000; Sherman et al. 1999; Vilchinsky and Kravetz 2005), as well as indicators of religious practices such as reading the Bible (Francis and Evans 1996; Francis 2000) and frequency of prayer and church attendance (Francis 2000; Steger and Frazier 2005).

There is a lack of research exploring the potential moderating effect of religious commitment on the link between religious faith and meaning in life. Religious denomination and faith do not seem to be factors sufficient to positively influence finding meaning in life. It is expected that the stronger religious faith of Polish students facilitates finding meaning in life, but only in the most religiously committed students.

Hypothesis 1 (H1). Religious commitment moderates the relationship between faith and meaning in life.

\section{Religiosity and Hope}

Many theories of hope are available (Stephenson 1991; Snyder 2000; Farran et al. 1995; Scioli et al. 2011; Nunn 1996), especially in nursing, where three hope scales have been used specifically with cancer patients (Herth 1991; Nowotny 1989). Between them exist many commonalities, which indicates the multidimensional character of this construct, consisting in particular of cognitive, affective, and agency factors. The affective component results from goal orientation being a motivating factor for sustaining activity and behaviors leading to achieving a desired goal (Averill et al. 1990; Miller and Powers 1988; Nunn 1996; Stephenson 1991). The cognitive component of hope refers to concentration on optimism 
regarding achieving goals (Farran et al. 1995; Nunn 1996). The agency dimension of hope concerns the conviction regarding performing the actions necessary to achieve planned goals (Snyder 2000). There are few studies examining how religion influences hope.

The literature shows that next to oncology patients (Bowes et al. 2002; Herth 1989; Zarzycka et al. 2019), students are the most frequent sample verified in reference to the relationship between religiosity and hope (Wnuk and Marcinkowski 2014; Chang et al. 2016; Nell and Rothmann 2018; Marques et al. 2013; Ciarrochi and Heaven 2012; Ahmed 2009). These pieces of research have confirmed that religiosity is positively related to hope. For example, in Polish students' spiritual experiences, the Daily Spiritual Experiences Scale was moderately and positively related to hope according to the Herth Hope Index (Wnuk and Marcinkowski 2014). Among Salvadoran youth, religiosity as a latent variable, whose indicators were religious event participation, the importance of being spiritual, and self-assessed spirituality, was a positive predictor of hope as measured by hopeful future expectations (King et al. 2020). In a sample of 430 South African university students, religiosity operationalized by self-rated religiosity, frequency of prayer, and frequency of religious services attendance positively affected both hope agency and the hope pathway (Nell and Rothmann 2018).

It is expected that generally faith enhances hope, but only in religiously committed students; in the group without religious commitment, this influence could be statistically insignificant.

Hypothesis 2 (H2). Religious commitment moderates the relationship between faith and hope.

\section{Religiosity and Gratitude}

Gratitude is a very valuable and desirable virtue in many religious traditions (Emmons and Kneezel 2005). In the literature, gratitude is operationalized as an emotion (Emmons and McCullough 2003), a character strength (Park et al. 2004), personality traits (McCullough et al. 2002), or a state variable in reaction to a specific situation (DeSteno et al. 2010). For religious people, gratitude toward God (Watkins et al. 2003) can be generalized as a tendency to be grateful for a person, nature, the universe, an animal, or even an employer (Friedman 1989; Teigen 1997; Wnuk 2020). For example, in a sample of US adults, religious commitment increased gratitude toward God, which in turn positively influenced general gratitude (Rosmarin et al. 2011). Additionally, in Krause and Hayward's study (2015), religious commitment and church attendance were positively correlated with gratitude to God.

Research into gratitude has focused on general or specific gratitude (Tsang et al. 2012). For example, in Wnuk's research (2018), gratitude toward an organization as a result of employees' spirituality increased job satisfaction and decreased stress at work. In another study, wives' prayers of gratitude also predicted husbands' marital satisfaction, but the reverse was not true (Fincham and May 2021).

Results of research have proven that general gratitude operationalized as a character trait was positively correlated with frequency of prayer (Lambert et al. 2009), church attendance (Watkins et al. 2003), general religiosity (Emmons and Kneezel 2005; McCullough et al. 2002), religious orientation (Watkins et al. 2003), religious coping (Emmons and Kneezel 2005), spiritual striving (Emmons and Kneezel 2005), and spiritual well-being (Mills et al. 2015). The most comprehensive study regarding the religion-gratitude relationship in a sample of nationally representative American youth from adolescence to young adulthood was conducted by Kraus et al. (2015). According to the achieved results, religious affiliation was related not to the level of gratitude but to other religious measures. Once all religious variables were introduced to the model of linear regression, only religious efficacy and possessing religious friends remained as predictors of gratitude (Kraus et al. 2015). Olson et al. (2019) have confirmed that intrinsic religiosity is related to increased self-reports of gratefulness but was unrelated to grateful behaviors or grateful emotions in response to a specific, standardized favor, which means that among intrinsically religiously 
motivated people, a religion-gratitude discrepancy was observed. We found no research in reference to the faith-gratitude relationship that used potential religious moderators. It is expected that for students with more than average religious commitment, faith will be more positively related to gratitude in comparison to groups presenting average and less-than-average commitment.

Hypothesis 3 (H3). Religious commitment moderates the relationship between faith and gratitude.

\section{Religiosity and Forgiveness}

Forgiveness is a moral virtue valued in many religious systems (McCullough and Worthington 1999) and especially emphasized in Christian spirituality (Shults and Sandage 2003), which treats forgiving one's enemies as an essential part of Christianity. In Christianity, God and Christ fill the role of models of forgiveness (Marty 1998). Forgiveness refers to a prosocial cognitive, emotional, and behavioral change in references to a transgressor; this forgiveness is reflected in the reduction of negative thoughts, emotions, and motivations toward the offender that might lead to a changed attitude towards the offender (Fehr et al. 2010). Forgiveness is examined both as a trait and as a state. The trait of forgivingness refers to a generalized disposition within a person to forgive across time, situations, and relationships. State forgiveness is related to person's forgiveness of a some kind of offense and the reaction to that situation. Besides forgiving a transgressor, one can forgive oneself for making mistakes, making wrong choices, or acting inappropriately; one can also receive forgiveness from God (Krause 2017; Huber et al. 2011).

Previous studies have confirmed that religiosity is positively correlated with the propensity to forgive, not only in Christian religious denominations but also among Muslims (Ayten 2012; Ghorbani et al. 2017). The premise is that this relationship is independent of religious affiliation. The achieved results are consistent with previous research confirming that positive religious coping (Sandage and Crabtree 2012), faith (Batson and Shwalb 2006), and prayer (Lawler-Row 2010) are positively related with forgiveness.

Recent research has confirmed the hypothesis about the discrepancy between religiosity and state forgiveness (McCullough and Worthington 1999; Davis et al. 2013; Tsang et al. 2005). Davis et al. (2013) found that the average correlation between religiosity and trait forgivingness was $r=0.29$, whereas the average correlation between religiosity and state forgiveness was $r=0.15$. Additionally, contextual religiosity measures were moderately related to state forgiveness $(r=0.31)$, whereas dispositional religiosity measures were weakly correlated with state forgiveness $(r=0.10)$.

Huber et al. (2011) found that the centrality of religiosity moderated the relationship between forgiveness by God and forgivingness. At a high level of religious centrality, forgiveness by God was positively correlated to forgivingness, but at a low level of religious centrality, this relationship was not statistically significant. This means that the beneficial effect of forgiveness by God on forgivingness was observed only in individuals for whom the religious construct system is central to their personality. It is expected that in students with a more-than-average religious commitment, faith will be positively related to forgivingness, but in groups with an average and less-than-average religious commitment, faith will not be related to either forgiveness aspect.

Hypothesis 4 (H4). Religious commitment moderates the relationship between faith and forgiveness.

\section{Materials and Methods}

\subsection{Participants}

The sample consisted of 393 medical students of physiotherapy, rehabilitation, and public health. All students confirmed they agreement in research participation. Questionnaires were distributed and completed during classes. 


\subsection{Measures}

The following measures were used: the Santa Clara Strength of Religious Faith Questionnaire (SCSORFQ), the Transgression-Related Interpersonal Motivations (TRIM) scale, the Purpose in Life (PIL) test, the Gratitude Questionnaire (GQ-6), the Herth Hope Index (HHI), and two one-item tools measuring religious practices such as frequency of prayer and frequency of Mass attendance.

\subsubsection{Demographics}

Women constituted $84.7 \%$ of the sample, while men constituted $15.3 \%$. Roman Catholics constituted $93.1 \%$ of the participants, and the remaining $6.9 \%$ were of different religions; $91.1 \%$ of the participants had secondary education, and $8.9 \%$ had higher education. The largest group of participants, $81.9 \%$, were aged between 20 and 30, 11.2\% were between 31 and 40,4.6\% were between 40 and 50, and 2.3\% were between 50 and 60 .

\subsubsection{Independent Variable}

Strength of religious faith. The SCSORFQ consists of 10 items, which respondents rated on a 5-point Likert scale from 1 (strongly disagree) to 5 (strongly agree). Studies have confirmed that this measure consists of one factor, which is called the strength of religious beliefs (Lewis et al. 2001; Wnuk 2017). The reliability of the scale is $\alpha=0.94-0.96$ (Plante and Boccaccini 1997a, 1997b; Wnuk 2017).

\subsubsection{Dependent Variables}

Forgiveness. The TRIM is used to measure motivation to forgive (McCullough et al. 1998). This measure consists of 12 items, 5 of which refer to revenge and 7 to avoiding the transgressor. Responses are given on a 5-point Likert scale from 1 (strongly disagree) to 5 (strongly agree). This scale has acceptable reliability, measured by relative stability (revenge: Cronbach's $\alpha=0.90$; avoidance: $\alpha=0.86-0.94$ ) and absolute stability, measured with test-retest reliability with an interval of 3 to 9 weeks (revenge: $\alpha=0.53-0.79$; avoidance: $\alpha=0.44-0.86$ ). The scale has acceptable internal validity, measured with factor analysis, as well as acceptable convergent and discriminant validity, measured by correlations with other measures of forgiveness and similar constructs (McCullough et al. 1998).

Gratitude. The GQ-6 is a one-factor measure with acceptable reliability (McCullough et al. 2002). In one of the studies, the test-retest reliability of this scale (Cronbach's $\alpha$ ) was 0.82 . The measure consists of six items, which respondents rate on a 7-point Likert scale from 1 (strongly disagree) to 7 (strongly agree). The ratings on individual items are added up.

Meaning in life. The PIL test consists of 20 items concerning meaning in life, which subjects respond to by indicating a field on the continuum ranging from 1 to 7 , where 7 represents the maximum level of meaning in life and 1 represents the minimum level. The score is computed by adding up the responses to all items. The higher the score, the stronger the satisfaction of the need for meaning in life; the lower the score, the greater the existential frustration (Cekiera 1985). The reliability of this test measured as Pearson's $r$ coefficient was 0.82; with the Spearman-Brown correction, it was 0.90 (Crumbaugh and Maholick 1964). For the Polish version of the scale, test-retest reliability with an interval of half a year ranged from 0.64 to 0.70 (Siek 1993).

Hope. The HHI consists of 12 items and is a measure of hope. Respondents rate each item on a 4-point Likert scale, from 1 (strongly disagree) to 4 (strongly agree; Herth 1992). The reliability of this measure assessed as Cronbach's $\alpha$ was 0.97 (Herth 1992); its test-retest reliability was 0.91 (Herth 2001).

\subsubsection{Moderator Variables}

Prayer. This variable was measured by using one question to which participants responded: never (1), sometimes (2), once monthly (3), once weekly (4), and every day (5).

Mass attendance. This variable attendance was verified based on a 5-point scale for how often a given individuals attended Mass. This consisted of (1) never, (2) one to two 
times a year, (3) three to six times a year, (4) once a month, (5) two to three times a month, and (6) two or more times a week.

Positive religious coping The Brief Religious Coping Scale (Brief RCOPE) consists of 14 items and half of them refers to positive and half to negative religious coping. Each question has a 4-point graded scale depending on how much the individuals agrees or disagrees with the question. The scale's reliability, depending on population, ranges from $\alpha=0.78-0.94$ (Pargament et al. 2000). In this research, only the items which refers to positive religious coping were used.

\subsection{Statistical Analyses}

Version of 27.0 IBM SPSS statistics software was used to calculate results. The Pearson correlation coefficient was used to estimate the associations between study variables. To verify moderating effect of prayer, attendance at Mass, and positive religious coping on strength of faith, meaning in life, hope, gratitude, revenge motivation, and avoidance motivation, the Process macro in SPPS was used (Hayes 2018). Five dependent variables were tested with three potential moderators. This means that 15 single regression models were used. In every linear regression, model number 1 of the Process macro, with probe interactions on -1 standard deviation $(-1 \mathrm{SD})$, mean and +1 standard deviation $(+1$ SD), and the Johnson-Neyman output were used. Probe interactions on -1 SD, mean, and +1 SD are three points along the scale of the (continuous) moderator variable $(W)$ conventionally chosen to represent "low", "medium", and "high" values on that variable (see, e.g., Aiken and West 1991). Using the Johnson-Neyman output, the relationship between the independent variable $(X)$ and the dependent variable $(Y)$ can be tested for range of significance across levels on the (assumed continuous) moderator variable $(W)$.

\section{Results}

Descriptive statistics are showed in Table 1 . The values of both skewness and kurtosis of the study variables were between -2 and 2 , which suggested that the distribution of these variables are close to normal distribution.

Table 1. Descriptive statistics for the study variables.

\begin{tabular}{cccccccccc}
\hline SCSORFQ & GQ-6 & $\begin{array}{c}\text { TRIM-12 } \\
\text { Revenge } \\
\text { Motivation }\end{array}$ & $\begin{array}{c}\text { TRIM-12 } \\
\text { Avoidance } \\
\text { Motivation }\end{array}$ & PIL & HHI & $\begin{array}{c}\text { Brief } \\
\text { RCOPE }\end{array}$ & Prayer & $\begin{array}{c}\text { Mass } \\
\text { Attendance }\end{array}$ \\
\hline$N$ & 393 & 393 & 393 & 393 & 393 & 393 & 393 & 393 & 393 \\
\hline Mean & 34.93 & 30.04 & 18.07 & 17.25 & 105.31 & 37.56 & 16.49 & 3.16 & 3.24 \\
\hline$S D$ & 8.77 & 5.93 & 4.08 & 6.70 & 17.18 & 4.26 & 3.53 & 1.49 & 1.51 \\
\hline Skewness & -0.49 & -0.55 & -0.95 & 0.21 & 0.18 & -0.42 & -0.29 & 0.12 & -0.09 \\
\hline Kurtosis & -0.22 & -0.20 & 1.40 & -0.99 & 0.83 & 0.40 & 1.09 & -1.61 & -1.34 \\
\hline Minimum & 10 & 11 & 5 & 7 & 61 & 25 & 6 & 1 & 1 \\
\hline Maximum & 50 & 42 & 25 & 32 & 164 & 47 & 25 & 5 \\
\hline Reliability & 0.94 & 0.70 & 0.82 & 0.91 & 0.74 & 0.76 & 0.87 & - \\
\hline
\end{tabular}

(Source: own study) SCSORFQ—Santa Clara Strength of Religious Faith Questionnaire; GQ-6-Gratitude Questionnaire; TRIM-12Transgression-Related Interpersonal Motivations Inventory; PIL—Purpose in Life Test; HHI-Herth Hope Index; Brief RCOPE—Brief Religious Coping Scale.

The obtained results of the correlation coefficients are shown in Table 2. The strength of religious faith was weakly correlated with all strengths of character besides revenge motivation, where this link was moderate. Positive religious coping was weakly and significantly correlated only with revenge motivation and avoiding motivation. Frequency of Mass attendance was significantly linked with meaning in life and revenge motivation. Frequency of prayer correlated with all strengths of character, and its correlations were 
weak except for revenge motivation and avoidance motivation, where these relationships were moderate. All religious variables were moderately positively correlated, which means that they were measures of different aspects of religiosity.

Table 2. Correlation matrix for research variables.

\begin{tabular}{lcccc}
\hline & $\begin{array}{c}\text { Religious } \\
\text { Faith }\end{array}$ & $\begin{array}{c}\text { Positive } \\
\text { Religious Coping }\end{array}$ & Prayer & $\begin{array}{c}\text { Mass } \\
\text { Attendance }\end{array}$ \\
\hline 1. Meaning of life & $0.16^{* *}$ & 0.01 & $0.24^{* *}$ & $0.29^{* *}$ \\
\hline 2. Hope & $0.13^{* *}$ & 0.05 & $0.20^{* *}$ & 0.04 \\
\hline 3. Gratitude & $0.11^{*}$ & -0.03 & $0.19^{* *}$ & 0.07 \\
\hline 4. Revenge motivation & $-0.34^{* *}$ & $-0.18^{* *}$ & $-0.45^{* *}$ & $-0.31^{* *}$ \\
\hline 5. Avoiding motivation & $-0.23^{* *}$ & $-0.12^{*}$ & $-0.36^{* *}$ & -0.08 \\
\hline 6. Positive religious coping & $0.62^{* *}$ & & $0.33^{* *}$ & $0.43^{* *}$ \\
\hline 7. Prayer & $0.61^{* *}$ & & & $0.52^{* *}$ \\
\hline 8. Mass attendance & $0.64^{* *}$ & & \\
\hline (Source: own study) & $p \leq 0.05^{* *} p \leq 0.01$. & &
\end{tabular}

The results of the interactional effect are shown in Table 3. The only case of significant interactional effect was the results of the probe interactions with the Johnson-Neyman output. These results for meaning of life are presented in Table 4, for hope in Table 5, for gratitude in Table 6, for revenge motivation in Table 7, and for avoidance motivation in Table 8.

Table 3. Results of moderation analyses.

\begin{tabular}{|c|c|c|c|c|c|c|c|c|}
\hline \multirow{2}{*}{ Hypotheses } & \multirow{2}{*}{$\begin{array}{l}\text { Moderating } \\
\text { Variable }\end{array}$} & \multirow{2}{*}{ Interaction Effect } & \multirow{2}{*}{ Coefficient } & \multirow{2}{*}{ SE } & \multirow{2}{*}{$\mathbf{t}$} & \multirow{2}{*}{$p$} & \multicolumn{2}{|c|}{$95 \% \mathrm{CL}$} \\
\hline & & & & & & & Low & High \\
\hline \multirow{3}{*}{$\begin{array}{c}\text { H } 1 \\
\text { (outcome: } \\
\text { meaning in } \\
\text { life) }\end{array}$} & Prayer & Faith $\times$ Prayer & 0.279 & 0.087 & 4.073 & 0.0001 & 0.144 & 0.414 \\
\hline & Mass attendance & Faith $\times$ Mass attendance & 0.286 & 0.069 & 4.152 & 0.0000 & 0.151 & 0.421 \\
\hline & $\begin{array}{l}\text { Positive religious } \\
\text { coping }\end{array}$ & $\begin{array}{c}\text { Faith } \times \text { Positive religious } \\
\text { coping }\end{array}$ & 0.661 & 0.0152 & 4.342 & 0.0000 & 0.036 & 0.096 \\
\hline \multirow{3}{*}{$\begin{array}{c}\text { H } 2 \\
\text { (outcome: } \\
\text { hope) }\end{array}$} & Prayer & Faith $\times$ Prayer & 0.077 & 0.016 & 4.694 & 0.0001 & 0.451 & 1.102 \\
\hline & Mass attendance & Faith $\times$ Mass attendance & 0.057 & 0.017 & 3.3 & 0.0011 & 0.023 & 0.091 \\
\hline & $\begin{array}{l}\text { Positive religious } \\
\text { coping }\end{array}$ & $\begin{array}{c}\text { Faith } \times \text { Positive religious } \\
\text { coping }\end{array}$ & 0.015 & 0.004 & 4.112 & 0.0000 & 0.008 & 0.023 \\
\hline \multirow{3}{*}{$\begin{array}{l}\text { H3 (outcome: } \\
\text { gratitude) }\end{array}$} & Prayer & Faith $\times$ Prayer & -0.023 & 0.023 & -0.995 & 0.3201 & -0.070 & 0.022 \\
\hline & Mass attendance & Faith $\times$ Mass attendance & -0.021 & 0.024 & -0.874 & 0.3828 & -0.069 & 0.026 \\
\hline & $\begin{array}{l}\text { Positive religious } \\
\text { coping }\end{array}$ & $\begin{array}{c}\text { Faith } \times \text { Positive religious } \\
\text { coping }\end{array}$ & 0.024 & 0.005 & 4.647 & 0.0000 & 0.013 & 0.034 \\
\hline \multirow{3}{*}{$\begin{array}{c}\mathrm{H} 4 \\
\text { (outcome: } \\
\text { tendency to } \\
\text { revenge) }\end{array}$} & Prayer & Faith $\times$ Prayer & -0.034 & 0.015 & -2.262 & 0.0243 & 0.063 & 0.004 \\
\hline & Mass attendance & Faith $\times$ Mass attendance & 0.013 & 0.016 & 0.800 & 0.4241 & -0.019 & 0.044 \\
\hline & $\begin{array}{l}\text { Positive religious } \\
\text { coping }\end{array}$ & $\begin{array}{c}\text { Faith } \times \text { Positive religious } \\
\text { coping }\end{array}$ & 0.006 & 0.003 & 1.818 & 0.0698 & -0.001 & 0.013 \\
\hline \multirow{3}{*}{$\begin{array}{c}\mathrm{H} 4 \\
\text { (outcome: } \\
\text { tendency to } \\
\text { avoid } \\
\text { transgressor) }\end{array}$} & Prayer & Faith $\times$ Prayer & 0.024 & 0.025 & 0.932 & 0.3517 & -0.026 & 0.073 \\
\hline & Mass attendance & Faith $\times$ Mass attendance & 0.111 & 0.026 & 4.23 & 0.0000 & 0.059 & 0.162 \\
\hline & $\begin{array}{l}\text { Positive religious } \\
\text { coping }\end{array}$ & $\begin{array}{c}\text { Faith } \times \text { Positive religious } \\
\text { coping }\end{array}$ & 0.033 & 0.006 & 5.904 & 0.0000 & 0.022 & 0.044 \\
\hline
\end{tabular}


Table 4. Conditional effects of meaning in life at values of moderators.

\begin{tabular}{ccccccc}
\hline & Effect & SE & $\mathbf{t}$ & $p$ & LLCI & ULCI \\
\hline $1.66(-1 S D)$ & -0.229 & 0.142 & -1.613 & 0.1074 & -0.507 & 0.050 \\
\hline $3.15(M)$ & 0.188 & 0.127 & 1.482 & 0.1394 & -0.062 & 0.438 \\
\hline $4.64(+1 S D)$ & 0.605 & 0.182 & 3.324 & 0.0010 & 0.247 & 0.963 \\
\hline \multicolumn{7}{c}{ Prayer as a moderator } \\
\hline $1.73(-1 S D)$ & -0.331 & 0.139 & -2.384 & 0.0176 & -0.604 & -0.058 \\
\hline $3.24(M)$ & 0.101 & 0.130 & 0.773 & 0.4398 & -0.156 & 0.357 \\
\hline $4.75(+1 S D)$ & 0.533 & 0.191 & 2.794 & 0.0055 & 0.158 & 0.908 \\
\hline $11.76(-1 S D)$ & 0.257 & 0.139 & 1.84 & 0.0661 & -0.017 & 0.530 \\
\hline $18.00(M)$ & 0.669 & 0.129 & 5.197 & 0.0000 & -0.416 & 0.922 \\
\hline $24.24(+1 S D)$ & 1.082 & 0.178 & 6.066 & 0.0000 & 0.731 & 1.433 \\
\hline \multicolumn{7}{c}{ Church attendance as a moderator } \\
\hline
\end{tabular}

(Source: own study) LLCI = 95\% Confidence Interval (Low); ULCI = 95\% Confidence Interval (High).

Table 5. Conditional effects of hope at values of moderators.

\begin{tabular}{ccccccc}
\hline & Effect & SE & $\mathbf{t}$ & $p$ & LLCI & ULCI \\
\hline $1.66(-1 S D)$ & -0.071 & 0.034 & -2.075 & 0.0368 & -0.138 & -0.037 \\
\hline $3.15(M)$ & 0.045 & 0.031 & 1.466 & 0.1434 & -0.015 & 0.105 \\
\hline $4.64(+1 S D)$ & 0.161 & 0.044 & 3.662 & 0.0003 & 0.074 & 0.247 \\
\hline \multicolumn{7}{c}{ Prayer as a moderator } \\
\hline $1.73(-1 S D)$ & 0.039 & 0.034 & 1.117 & 0.2647 & -0.030 & 0.107 \\
\hline $3.24(M)$ & 0.125 & 0.033 & 3.823 & 0.0003 & 0.061 & 0.189 \\
\hline $4,75(+1 S D)$ & 0.211 & 0.048 & 4.415 & 0.0000 & 0.117 & 0.305 \\
\hline $11.76(-1 S D)$ & 0.020 & 0.034 & 0.594 & 0.5529 & -0.047 & 0.087 \\
\hline $18.00(M)$ & 0.116 & 0.031 & 3.676 & 0.0003 & 0.054 & 0.177 \\
\hline $24.24(+1 S D)$ & 0.211 & 0.044 & 4.845 & 0.0000 & 0.125 & 0.297 \\
\hline
\end{tabular}

(Source: own study) LLCI = 95\% Confidence Interval (Low); ULCI = 95\% Confidence Interval (High).

Table 6. Conditional effects of gratitude at values of moderator (positive religious coping).

\begin{tabular}{ccccccc}
\hline & Effect & SE & $\mathbf{t}$ & $p$ & LLCI & ULCI \\
\hline $11.76(-1 S D)$ & 0.045 & 0.046 & 0.959 & 0.3379 & -0.047 & 0.136 \\
\hline $18.00(M)$ & 0.192 & 0.043 & 4.666 & 0.0000 & 0.107 & 0.276 \\
\hline $24.24(+1 S D)$ & 0.339 & 0.059 & 5.7 & 0.0000 & 0.222 & 0.456 \\
\hline
\end{tabular}

Positive religious coping as a moderator

(Source: own study) LLCI = 95\% Confidence Interval (Low); ULCI = 95\% Confidence Interval (High). 
Table 7. Conditional effects of tendency to revenge at values of moderator.

\begin{tabular}{ccccccc}
\hline & Effect & SE & $\mathbf{t}$ & $p$ & LLCI & ULCI \\
\hline $1.66(-1 S D)$ & -0.078 & 0.031 & -2.553 & 0.0110 & -0.139 & -0.018 \\
\hline $3.15(M)$ & -0.028 & 0.027 & -1.027 & 0.3051 & -0.026 & 0.082 \\
\hline $4.64(+1 S D)$ & 0.022 & 0.039 & 0.555 & 0.5793 & -0.099 & 0.056 \\
\hline \multicolumn{7}{c}{ Prayer as a moderator } \\
\hline
\end{tabular}

(Source: own study) LLCI = 95\% Confidence Interval (Low); ULCI = 95\% Confidence Interval (High).

Table 8. Conditional effects of tendency to avoid transgressor at values of moderator.

\begin{tabular}{ccccccc}
\hline & Effect & SE & $\mathbf{t}$ & $p$ & LLCI & ULCI \\
\hline $1.73(-1 S D)$ & -0.132 & 0.053 & -2.502 & 0.0128 & -0.236 & -0.028 \\
\hline $3.24(M)$ & -0.299 & 0.050 & -6.041 & 0.0002 & -0.397 & -0.202 \\
\hline $4.75(+1 S D)$ & -0.467 & 0.072 & -6.439 & 0.0000 & -0.609 & -0.117 \\
\hline \multicolumn{7}{c}{ Church attendance as a moderator } \\
\hline $11.76(-1 S D)$ & -0.058 & 0.051 & -1.142 & 0.2542 & -0.042 & 0.159 \\
\hline $18.00(M)$ & -0.264 & 0.047 & -5.591 & 0.0000 & -0.356 & -0.171 \\
\hline $24.24(+1 S D)$ & -0.469 & 0.065 & -7.782 & 0.0000 & -0.597 & -0.222 \\
\hline \multicolumn{7}{c}{ Positive religious coping as a moderator } \\
\hline (Source: own study) LLCI $=95 \%$ Confidence Interval (Low); ULCI = 95\% Confidence Interval (High).
\end{tabular}

Significant moderating effects of prayer, attendance at Mass, and positive religious coping on strength of faith and meaning in life were confirmed (see Table 3). Only for students praying more frequently than average was a relationship between faith and finding meaning in life statistically significant. In a sample of both average and lowerthan-average praying students, the relationship between faith and meaning in life was not statistically significant. This means that the beneficial effect of faith for meaning in life is available only to students who pray more frequently than average. Faith positively influenced meaning in life only for students who participated in Holy Mass more often than average. For average Mass participants, there was no statistically significant effect, but for lower-than-average participants, this influence was negative. This means that for students who attend Mass most frequently, faith facilitates finding meaning in life, but for those who participate less frequently, faith has a negative effect on finding meaning in life. Additionally, the positive effect of faith on meaning in life was noticed only in a sample of those who struggle with stress using positive religious coping with an average or more-than-average frequency.

Faith was not correlated with hope among the group of students whose prayer was of an average frequency. For students whose prayer was more frequent than average, faith enhanced hope, but for students whose prayer was less frequent than average, faith reduced hope. For students who attended Mass and used positive religious coping less frequently than average, faith was not related to hope. Among students with average and more-frequent-than-average Mass attendance and who used positive religious coping, faith enhanced hope.

For both prayer and Mass attendance, there were no statistically significant interaction effect of these variables and faith on gratitude (see Table 3). A positive effect of faith on gratitude was observed among students with an average or more-than-average frequency of use of positive religious coping.

Neither attendance at Mass nor positive religious coping moderated the relationship between faith and revenge motivation. Unexpectedly, only for the group of students whose praying was of less-than-average frequency did faith reduce motivation for revenge. In the rest of both groups, there was no correlation between strength of religious faith and motivation for revenge. 
Strength of religious faith significantly reduced motivation to avoid transgressors regardless of Mass attendance, but the highest effect was noticed in the group of students that used this religious practice more often than average, and the smallest effect concerned students with less-than-average participation in Mass. Only for students who used religious coping with an average or greater-than-average frequency did faith reduce the tendency to avoid transgressors. Among students with a lower-than-average use of religious coping, faith was not connected with avoidance motivation.

\section{Discussion}

The purpose of the research was the verification of whether the relationships between faith and some strengths of character are moderated by religious commitment. Like religious affiliation, faith seems not to be a sufficient factor for shaping strengths of character if it is not reflected in religious commitment. Recent studies have indicated that religious orientation is a moderating variable between religiosity and hope, meaning in life, gratitude, and forgivingness, suggesting that only in intrinsically religiously motivated believers whose religion is a central value, reflected in many aspects of their lives, does religion generate a positive outcome. It was supposed that only for religiously committed students did faith have a positive influence on chosen strengths of character. The hypothesis regarding religious commitment as a moderator of the association between faith and meaning in life was totally confirmed, and a moderating effect was observed in references to all religious commitment indicators. Only for students who participate in religious practices more frequently than average did faith facilitate finding meaning in life. For students who attended Mass less frequently than average, faith negatively influenced finding meaning in life. Additionally, students using positive religious coping with an average or morethan-average frequency found it easier to find meaning in life. The obtained results are consistent with recent studies indicating that without religious commitment and religious values as central elements of life, faith and religious affiliation are not sufficient factors for finding purpose and meaning in life (Berthold and Ruch 2014; Hui and Fung 2008; Francis et al. 2010). Religion can also be a meaning-oriented system among populations less religious than women students from Poland. For example, in a sample of randomly selected prisoners in Texas representing different religious denominations, religiosity as a factor consisted of perceived closeness to God, religious salience, religious service attendance, praying, and reading a sacred text, which were positively related to the presence of meaning in life (Jang et al. 2018).

Additionally, the hypothesis about the moderating role of religious commitment in the relationship between faith and hope was totally confirmed. For students attending Mass and coping with stress based on positive references to God and religion with an average and more-than-average frequency, faith is a positive way to enhance hope. Among the group of students praying and using religious coping less often than average, faith does not fill this positive role for hope; according to the results, frequency of prayer is an important factor shaping their hope. For students praying more frequently than average, faith leads to increased hope, but for students praying less frequently than average, faith leads to reduced hope. This positive effect of faith on hope was greater when prayer was practiced often, and conversely, the negative influence was greater when prayer occurred less often.

The hypothesis regarding religious commitment as a moderator of faith and gratitude was partially confirmed. Inconsistent with expectations, neither attendance at Mass nor prayer moderated the relationship between faith and gratitude. For students using positive religious coping on average or more often than average, this way of struggling with stress has a beneficial influence on gratitude. As in the research of Lambert et al. (2009), frequency of prayer was positively related to gratitude, but inconsistent with Watkins et al. (2003) and Emmons and Kneezel (2005); Mass attendance and positive religious coping were not statistically correlated with gratitude. 
The hypothesis about the moderating role of forgiveness in the relationship between faith and gratitude was partially confirmed. Regarding revenge motivation, the moderating effect of religious commitment was noticed only in reference to prayer. Unexpectedly, for students praying less frequently than average, faith reduced motivation for revenge, but for students praying with average frequency and more frequently than average, this relationship was not statistically significant. This means that faith has a positive effect on the tendency to revenge only in the group of students whose prayer is less frequent than average. Frequency of prayer did not moderate the link between faith and the motivation to avoid transgressors. This relationship was moderated by the frequency of attendance at Mass and positive religious coping. For students who participate in Mass and use positive religious coping with an average or greater-than-average frequency when confronted with stress, faith reduced motivation to avoid transgressors, but for students attending Mass less frequently than average, faith increased this tendency. Consistent with previous research, the tendency to forgive was related to positive religious coping (Sandage and Crabtree 2012), faith (Batson and Shwalb 2006), and prayer (Lawler-Row 2010).

The results can be interpreted based on religion as a meaning framework. This meaning system offers believers a structure providing a set of beliefs, desires, and guidelines regarding how to live; it facilitates perception, understanding, and the evaluation of experiences from the religious perspective (Silberman 2005; McIntosh 1995). From this point of view, faith is only one element of this structure, and without religious commitment, faith is not sufficient to enable students to find meaning in life or to enhance their hope. Religious practices did not influence the relationship between faith and gratitude, and, unexpectedly, faith among students who prayed less frequently than average had reduced revenge motivation. This differences between hope and meaning in life as dependent variables, in comparison to gratitude and tendency to revenge, can be explained by social reasons. Both meaning in life and hope are issues that every human being faces as an individual, and society does not especially motivate its members to find meaning in life or shape hope.

In reference to gratitude and lack of motivation to revenge, there is social pressure that causes people to view these traits as desirable, and society also stigmatizes those who lack such virtues, which provides an incentive to develop them. For example, the reciprocity norm (Gouldner 1960) as a central element of social exchange (Blau 1964) obligates a person who receives something valuable or support or help to be grateful and reciprocate by acting for the benefit of the donor. Failure to meet this obligation causes social stigma and results in the person being labeled as ungrateful.

A similar situation is found regarding forgiveness. Some forms of revenge can be penalized, but social control of this kind of behavior is regulated within the legal system sanctioned by society. In other words, faith is probably a factor sufficient to shape gratitude and the tendency to revenge independent of religious practices because cultural and social elements strengthen grateful and nonvengeful behaviors.

The present research carries some theoretical and practical implications. It confirms that the relationship between religiosity and some strengths of character are complex and depend on what religious measure is used. It has been proven that next to religious orientation (Hui and Fung 2008; Francis et al. 2010; Sandage and Harden 2011; Watkins et al. 2003), religious commitment moderates the relationships between faith and meaning in life, hope, gratitude, and forgiveness. In reference to meaning in life and hope as dependent variables, a moderating effect was observed for all measures of religious commitment, in reference to avoidance motivation for two measures of religious commitment, and in the case of gratitude and revenge motivation for one indicator of religious commitment. It was proven that faith without religious commitment does not influence meaning in life and hope in students, nor does it enhance gratitude and reduce motivation to avoid transgressors without the use of positive religious coping at an average or more-frequentthan-average level. 
From a practical point of view, the results provide an incentive for counselors and psychologists to engage religiously affiliated adolescents who hold faith in religious commitment as a way to facilitate meaning in life, enhance hope, and increase gratitude and forgiveness. For this group of students, preparation and implementation training and workshops focusing on motivation to religious commitment could have positive effects in developing some strengths of character, such as meaning in life, hope, gratitude, and forgiveness.

\section{Limitations and Future Research}

The research has some limitations.

Firstly, the generalizability of the achieved results is limited to Roman Catholic students from Poland, mostly women with a secondary education. The research sample was not randomly selected from the whole population of Polish students. The procedure of the selection was limited to the students from medical fields of study. More research is needed to verify the potential influence of sex and age on relationships between faith and strengths of character. It is important to know whether in other research samples-for example, among representatives of other religious affiliation or students from the other cultural contexts (conditions) - religious commitment moderates relationships between faith and strengths of character. According to previous research in more religious nations, religion affects positive outcomes among religious individuals (Stavrova et al. 2013; Diener et al. 2011). Additionally, in national cultures where socialization of religious faith is more common, religious practices are related to subjective well-being, whereas in cultures where religious socialization is less prevalent, the relationship between religious practices and subjective well-being is reversed (Lun and Bond 2013). Poland is a highly religious nation. In the opinion of $64 \%$ of Poles, Christianity is significant component of their nationality and is related to public and private religious practices. Attendance at religious services at least monthly was claimed by $61 \%$ of Poles, a higher proportion than in any other European country. Daily prayer was declared by $27 \%$ of the Polish population (Pew Research Center 2018). Additionally, in Poland, socialization of religious faith is a common phenomenon (Lun and Bond 2013). Verification of the moderating effect of religious commitment on the relationship between faith and strengths of character in nations significantly less religious than Poland, where religious socialization is less prevalent, could provide interesting results.

An additional limitation of the study is the theoretical similarity of the some items part of the measures such as SCSORFQ, HHI, and frequency of prayer. For example, SCSORFQ consists of item "I pray daily", and prayer as a moderator was verified using answers regarding the frequency of prayer. Additionally, $\mathrm{HHI}$ consists of the item "I have a faith that gives me comfort", and SCSORFQ was used for the strength of faith verification. This does not mean that these constructs are the same, but they have some similarities, and the best proof of this is the weak correlation between SCSORFQ and HHI in a sample of students not divided based on average religious commitment, less than average commitment, and more than average committed, as well as the moderate correlation between SCSORFQ and frequency of prayer as a two other aspects of religiousness.

It could also be interesting to verify whether other religious variables such as religious orientation or religious support or some spiritual aspects of life are moderating variables for relations of faith and strengths of character using other character strengths connected to religion such as humility or patience.

Future research should employ other measures of meaning in life, hope, gratitude, and forgiveness for comparison with the present results. It is suggested to use not only generalized measures of gratitude and forgiveness but, for example, gratitude toward specific entities such as God (Watkins et al. 2003) or organizations (Wnuk 2020) and forgiveness of self and forgiveness from God (Krause 2017).

The cross-sectional design of this study limits the interpretation of the results to correlations between variables and eventually the direction of relationships between them. 
Longitudinal studies are needed for a deeper understanding of the complexity of relationships between some religious facets and strengths of character from a causality point of view.

Funding: This study was funded by author sources.

Institutional Review Board Statement: Ethical review and approval were waived for this study, due to non-potential harming influence.

Informed Consent Statement: Informed consent was obtained from all subjects involved in the study.

Data Availability Statement: The data presented in this study are available on request from the corresponding author. The data are not publicly available due to privacy of the participants.

Conflicts of Interest: The author declares no conflict of interest.

\section{References}

Ahmed, Sameera. 2009. Religiosity and presence of character strengths in american muslim youth. Journal of Muslim Mental Health 4: 104-23. [CrossRef]

Aiken, Leona S., and Stephen G. West. 1991. Testing and Interpreting Interactions in Multiple regrEssion. New York: Sage Publications.

Allport, W. Gordon, and Michael J. Ross. 1967. Personal religious orientation and prejudice. Journal of Personality and Social Psychology 5: 432-43. [CrossRef]

Ardelt, Monika, and Cynthia S. Koenig. 2006. The role of religion for hospice patients and relatively healthy older adults. Research on Aging 28: 184-215. [CrossRef]

Ardelt, Monika. 2003. Effects of religion and purpose in life on elders' subjective well-being and attitudes toward death. Journal of Religious Gerontology 14: 55-77. [CrossRef]

Auhagen, Ann Elisabeth. 2000. On the psychology of meaning of life. Swiss Journal of Psychology 59: 34-48. [CrossRef]

Averill, James R., George Catlin, and Kyum Koo Chon. 1990. Rule of Hope. New York: Springer.

Ayten, Ali. 2012. How religion promotes forgiveness: The case of turkish muslims. Archiv Fur Religionspsychologie/Archive for the Psychology of Religion 34: 411-25. [CrossRef]

Batson, Mindi D., and David W. Shwalb. 2006. Forgiveness and religious faith in Roman Catholic married couples. Pastoral Psychology 55: 119-29. [CrossRef]

Berthold, Anne, and Willibald Ruch. 2014. Satisfaction with life and character strengths of non-religious and religious people: It's practicing one's religion that makes the difference. Frontiers in Psychology 5: 876. [CrossRef] [PubMed]

Blau, Peter M. 1964. Exchange and Power in Social Life. New York: John Wiley \& Sons.

Bowes, Denise E., Deborah Tamlyn, and Lorna J. Butler. 2002. Women living with ovarian cancer: Dealing with an early death. Health Care for Women International 23: 135-48. [CrossRef]

Cekiera, Czesław. 1985. Toxic Obsession, Drug Addiction, Medicine Addiction, Alcoholism, Nicotine Addiction. Warsaw: The State Scientific.

Chang, Edward C., Zunaira Jilani, Erin E. Fowler, Tina Yu, Shao Wei Chia, Elizabeth A. Yu, Hannah K. McCabe, and Jameson K. Hirsch. 2016. The relationship between multidimensional spirituality and depressive symptoms in college students: Examining hope agency and pathways as potential mediators. The Journal of Positive Psychology 11: 189-98. [CrossRef]

Ciarrochi, Joseph, and Patrick C. L. Heaven. 2012. Religious values and the development of trait hope and self-esteem in adolescents. Journal for the Scientific Study of Religion 51: 676-88. [CrossRef]

Crumbaugh, James C., and Leonard T. Maholick. 1964. An experimental study in existentialism: The psychometric approach to Frankl's concept of noogenic neurosis. Journal of Clinical Psychology 20: 200-7. [CrossRef]

Dahlsgaard, Katherine, Christopher Peterson, and Martin E. P. Seligman. 2005. Shared virtue: The convergence of valued human strengths across cultures and history. Review of General Psychology: Journal of Division 1, of the American Psychological Association 9: 203-13. [CrossRef]

Davis, Don E., Everett L. Worthington, Joshua N. Hook, and Peter C. Hill. 2013. Research on religion/spirituality and forgiveness: A meta-analytic review. Psychology of Religion and Spirituality 5: 233-41. [CrossRef]

Davis, Don E., Joshua N. Hook, Daryl R. Van Tongeren, Aubrey L. Gartner, and Everett L. Worthington Jr. 2012. Can religion promote virtue?: A more stringent test of the model of relational spirituality and forgiveness. International Journal for the Psychology of Religion 22: 252-66. [CrossRef]

DeSteno, David, Monica Y. Bartlett, Jolie Baumann, Lisa A. Williams, and Leah Dickens. 2010. Gratitude as moral sentiment: Emotion-guided cooperation in economic exchange. Emotion 10: 289-93. [CrossRef]

Diener, Ed, Louis Tay, and David G. Myers. 2011. The religion paradox: If religion makes people happy, why are so many dropping out? Journal of Personality and Social Psychology 101: 1278-90. [CrossRef]

Emmons, Robert A., and Michael E. McCullough. 2003. Counting blessings versus burdens: An experimental investigation of gratitude and subjective wellbeing in daily life. Journal of Personality and Social Psychology. 84: 377-89. [CrossRef] 
Emmons, Robert A., and Teresa T. Kneezel. 2005. Giving thanks: Spiritual and religious correlates of gratitude. Journal of Psychology and Christianity 24: 140-48.

Farran, Carol, Kaye A. Herth, and Judith. M. Popovich. 1995. Hope and Hopelessness: Critical Clinical Constructs. Thousand Oaks: Sage Publications.

Fehr, Ryan, Michele J. Gelfand, and Monisha Nag. 2010. The road to forgiveness: A meta-analytic synthesis of its situational and dispositional correlates. Psychological Bulletin 136: 894-914. [CrossRef]

Fincham, Frank D., and Ross W. May. 2021. Generalized gratitude and prayers of gratitude in marriage. The Journal of Positive Psychology 16: 282-87. [CrossRef]

Fletcher, Susan K. 2004. Religion and life meaning: Differentiating between religious beliefs and religious community in constructing life meaning. Journal of Aging Studies 18: 171-85. [CrossRef]

Francis, J. Leslie, and Thomas E. Evans. 1996. The relationship between personal prayer and purpose in life among churchgoing and non-churchgoing twelve-to-fifteen-year-olds in the UK. Religious Education 99: 9-21. [CrossRef]

Francis, Leslie, Albert Jewell, and Mandy Robbins. 2010. The relationship between religious orientation, personality, and purpose in life among an older Methodist sample. Mental Health, Religion E Culture 13: 7-8.

Francis, Leslie. 2000. The relationship between bible reading and purpose in life among 13-15-year-olds. Mental Health, Religion $\mathcal{E}$ Culture 3: 27-36.

Frankl, Viktor E. 1998. Homo Patiens. Warsaw: Pax Publishing Institute.

Frankl, Viktor E. 2009. Man's Search for Meaning. Warsaw: Black Sheep Press.

French, Sarah, and Stephen Joseph. 1999. Religiosity and its association with happiness, purpose in life, and self-actualisation. Mental Health, Religion \& Culture 2: 117-20.

Friedman, Philip H. 1989. Creating Well-Being: The Healing Path to Love, Peace, Self-Esteem, and Happiness. Saratoga: R \& E Publishers.

Ghorbani, Nima, Hamed Kashanaki, P. J. Watson, and Zhuo Job Chen. 2017. Diversity and complexity of religion and spirituality in Iran: Relationships with self-compassion and self-forgiveness. International Journal for the Psychology of Religion 27: 157-71. [CrossRef]

Gouldner, Alvin W. 1960. The Norm of Reciprocity a Preliminary Statement. Indianapolis: Bobbs-Merrill.

Hardy, Sam A., and Pamela E. King. 2019. Processes of religious and spiritual influence in adolescence: Introduction to a special section. Journal of Research on Adolescence 29: 244-53.

Hardy, Sam A., Jenae M. Nelson, Joseph P. Moore, and Pamela E. King. 2019. Processes of religious and spiritual influence in adolescence: A systematic review of 30 years of research. Journal of Research on Adolescence 29: 254-75. [CrossRef]

Hayes, Andrew F. 2018. Introduction to Mediation, Moderation, and Conditional Process Analysis: A Regression-Based Approach. New York: Guilford Press.

Herth, Kaye. 1989. The relationship between level of hope and level of coping response and other variables in patients with cancer. Oncology Nursing Forum 16: 67-72.

Herth, Kaye. 1991. Development and refinement of an instrument to measure hope. Scholarly Inquiry for Nursing Practice 5: 39-51.

Herth, Kaye. 1992. Abbreviated instrument to measure hope: Development and psychometric evaluation. Journal of Advanced Nursing 17: 1251-59. [CrossRef] [PubMed]

Herth, K. A. 2001. Development and implementation of a Hope Intervention Program. Oncology Nursing Forum 28: 1009-16. [PubMed]

Huber, S., Susanne Huber, and Odilo W. Huber. 2011. Forgiveness by God and human forgivingness: The centrality of the religiosity makes the difference. Archiv Fur Religionspsychologie/Archive for the Psychology of Religion 33: 115-34. [CrossRef]

Hui, Victoria Ka-Ying, and Helene Fung. 2008. The relationship between religious orientation, personality, and purpose in life among an older Methodist sample. Death Studies 33: 30-50. [CrossRef]

Jang, Sung J., Byron R. Johnson, Joshua Hays, Michael Hallett, and Grant Duwe. 2018. Existential and virtuous effects of religiosity on mental health and aggressiveness among offenders. Religions 9: 182. [CrossRef]

Jim, Heather S., Susan A. Richardson, Deanna M. Golden-Kreutz, and Barbara L. Andersen. 2006. Strategies used in coping with a cancer diagnosis predict meaning in life for survivors. Health Psychology: Official Journal of the Division of Health Psychology, American Psychological Association 25: 753-61. [CrossRef]

King, Pamela Ebstyne, Jennifer Medina Vaughn, Yeonsoo Yoo, Jonathan M. Tirrell, Elizabeth M. Dowling, Richard M. Lerner, G. John Geldhof, Jacqueline V. Lerner, Guillermo Iraheta, Kate Williams, and et al. 2020. Exploring Religiousness and Hope: Examining the Roles of Spirituality and Social Connections among Salvadoran Youth. Religions 11: 75. [CrossRef]

Kor, Ariel, Steven Pirutinsky, Mario Mikulincer, Anat Shoshani, and Lisa Miller. 2019. A longitudinal study of spirituality, character strengths, subjective well-being, and prosociality in middle school adolescents. Frontiers in Psychology 10: 377. [CrossRef]

Kraus, Rachel, Scott A. Desmond, and Zachary D. Palmer. 2015. Being thankful: Examining the relationship between young adult religiosity and gratitude. Journal of Religion and Health 54: 1331-44. [CrossRef] [PubMed]

Krause, Neal, and R. David Hayward. 2015. Humility, Compassion, and Gratitude to God: Assessing the Relationships among Key Religious Virtues. Psychology of Religion and Spirituality 7: 192-204. [CrossRef]

Krause, Neal. 2017. Religious involvement and self-forgiveness. Mental Health, Religion E Culture 20: 128-42.

Lambert, Nathaniel M., Steven M. Graham, Frank D. Fincham, and Tyler F. Stillman. 2009. A changed perspective: How gratitude can affect sense of coherence through positive reframing. The Journal of Positive Psychology 6: 461-70. [CrossRef] 
Lawler-Row, Kathleen A. 2010. Forgiveness as a mediator of the religiosity-Health relationship. Psychology of Religion and Spirituality 2: 1-16. [CrossRef]

Lewis, Christopher Alan, Mark Shevlin, Conor McGuckin, and Marek Navrátil. 2001. The Santa Clara Strength of Religious Faith Questionnaire: Confirmatory Factor Analysis. Pastoral Psychology 49: 379-84. [CrossRef]

Lun, Vivian Miu-Chi, and Michael Harris Bond. 2013. Examining the relation of religion and spirituality to subjective well-being across national cultures. Psychology of Religion and Spirituality 5: 304-15. [CrossRef]

Maltby, John. 2002. The Age Universal I-E Scale-12 and orientation toward religion: Confirmatory factor analysis. Journal of Psychology 136: 555-60. [CrossRef]

Marques, Susana C., Shane J. Lopez, and Joanna Mitchell. 2013. The Role of Hope, Spirituality and Religious Practice in Adolescents' Life Satisfaction: Longitudinal Findings. Journal of Happiness Studies 14: 251-61. [CrossRef]

Marty, Martin E. 1998. The ethos of Christian forgiveness. In Dimensions of Forgiveness. Edited by Everett L. Worthington Jr. Philadelphia: Templeton Foundation Press, pp. 9-28.

McCullough, Michael E., and Everett L. Worthington Jr. 1999. Religion and the forgiving personality. Journal of Personality 67: 1141-64. [CrossRef] [PubMed]

McCullough, Michael E., Robert A. Emmons, and Jo-Ann Tsang. 2002. The grateful disposition: A conceptual and empirical topography. Journal of Personality and Social Psychology 82: 112-27. [CrossRef] [PubMed]

McCullough, Michael E., Jo-Ann Tsang, and Robert A. Emmon. 2004. Gratitude in intermediate affective terrain: Links of grateful moods to individual differences and daily emotional experience. Journal of Personality and Social Psychology 86: 295-309. [CrossRef]

McCullough, Michael E., K. Chris Rachal, Steven J. Sandage, Everett L. Worthington, Susan Wade Brown, and Terry L. Hight. 1998. Interpersonal forgiving in close relationships: II. Theoretical elaboration and measurement. Journal of Personality and Social Psychology 75: 1586-603. [CrossRef] [PubMed]

McIntosh, Daniel N. 1995. Religion-as-Schema, With Implications for the Relation Between Religion and Coping. The International Journal for the Psychology of Religion 5: 1-16. [CrossRef]

Miller, Judith F., and Marjorie J. Powers. 1988. Development of an instrument to measure hope. Nursing Research 37: 6-10. [CrossRef] [PubMed]

Mills, Paul J., Laura Redwine, Kathleen Wilson, Meredith A. Pung, Kelly Chinh, Barry H. Greenberg, Ottar Lunde, Alan Maisel, Ajit Raisinghani, Alex Wood, and et al. 2015. The role of gratitude in spiritual well-being in asymptomatic heart failure patients. Spirituality in Clinical Practice (Washington DC) 2: 5-17. [CrossRef]

Nell, Werner, and Sebastiaan Rothmann. 2018. Hope, religiosity, and subjective well-being. Journal of Psychology in Africa 28: 253-60. [CrossRef]

Nowotny, M. L. 1989. Assessment of hope in patients with cancer: Development of an instrument. Oncology Nursing Forum 16: 75-79.

Nunn, Kenneth P. 1996. Personal hopefulness: A conceptual review of the relevance of the perceived future to psychiatry. British Journal of Medical Psychology 63: 227-45. [CrossRef]

Olson, Rebecca, Amy Knepple Carney, and Julie Hicks Patrick. 2019. Associations between gratitude and spirituality: An experience sampling approach. Psychology of Religion and Spirituality 11: 449-52. [CrossRef]

Pargament, Kenneth I., Harold G. Koenig, and Lisa M. Perez. 2000. The many methods of religious coping: Development and initial validation of the RCOPE. Journal of Clinical Psychology 56: 519-43. [CrossRef]

Pargament, Kenneth, Margaret Feuille, and Burdzy Donna. 2011. The Brief RCOPE: Current psychometric status of a short measure of religious coping. Religions 2: 51-76. [CrossRef]

Park, Nansook, Christopher Peterson, and Martin E. P. Seligman. 2004. Strengths of character and well-Being. Journal of Social and Clinical Psychology 23: 603-19. [CrossRef]

Pew Research Center. 2018. Eastern and Western Europeans Differ on Importance of Religion, Views of Minorities, and Key Social Issues. Available online: https:/ / www.pewforum.org/2018/10/29/eastern-and-western-europeans-differ-on-importance-ofreligion-views-of-minorities-and-key-social-issues/ (accessed on 17 September 2021).

Plante, Thomas G., and Marcus T. Boccaccini. 1997a. The Santa Clara Strength of Religious Faith Questionnaire. Pastoral Psychology 45: 375-87. [CrossRef]

Plante, Thomas G., and Marcus Boccaccini. 1997b. Reliability and validity of the Santa Clara Strength of Religious Faith Questionnaire. Pastoral Psychology 45: 429-37. [CrossRef]

Plante, Thomas G., Scott Yancey, Allen Sherman, and Mira Guertin. 2000. The association between strength of religious faith and psychological functioning. Pastoral Psychology 48: 405-12. [CrossRef]

Root, Luna Lindsey M., Daryl R. Van Tongeren, and Charlotte van Oyen Witvliet. 2017. Virtue, positive psychology, and religion: Consideration of an overarching virtue and an underpinning mechanism. Psychology of Religion and Spirituality 9: $299-302$. [CrossRef]

Rosmarin, David, Steven Pirutinsky, Adam Cohen, Yardana Galler, and Elizabeth Krumrei. 2011. Grateful to God or just plain grateful? A comparison of religious and general gratitude. The Journal of Positive Psychology 6: 389-96. [CrossRef]

Sandage, Steven J., and Sarah Crabtree. 2012. Spiritual pathology and religious coping as predictors of forgiveness. Mental Health, Religion E Culture 15: 689-707.

Sandage, Steven, and Mark Harden. 2011. Relational spirituality, differentiation of self, and virtue as predictors of intercultural development. Mental Health, Religion \& Culture 14: 819-38. 
Schnitker, Sarah A., and Robert A. Emmons. 2007. Patience as a virtue: Religious and psychological perspectives. Research in the Social Scientific Study of Religion 18: 177-208.

Schnitker, Sarah A., Benjamin Houltberg, William Dyrness, and Nanyamka Redmond. 2017. The virtue of patience, spirituality, and suffering: Integrating lessons from positive psychology, psychology of religion, and Christian theology. Psychology of Religion and Spirituality 9: 264-75. [CrossRef]

Scioli, Anthony, Michael Ricci, Than Nyugen, and Erica R. Scioli. 2011. Hope: Its nature and measurement. Psychology of Religion and Spirituality 3: 78-97. [CrossRef]

Sharma, Swati, and Kamlesh Singh. 2018. Religion and well-Being: The mediating role of positive virtues. Journal of Religion and Health 58: 119-31. [CrossRef]

Sherman, Allen C., Thomas G. Plante, Stephanie Simonton, Dawn C. Adams, S. Kaay Burris, and Casey Harbison. 1999. Assessing religious faith in medical patients: Cross-Validation of the Santa Clara Strength of Religious Faith Questionnaire. Pastoral Psychology 48: 129-41. [CrossRef]

Shults, F. LeRon, and Steven J. Sandage. 2003. The Faces of Forgiveness: Searching for Wholeness and Salvation. Grand Rapids: Baker Academic.

Siek, Stanisław. 1993. Selected Methods of Personality Testing. Warsaw: Academy of Catholic Theology.

Silberman, Israela. 2005. Religion as a Meaning System: Implications for the New Millennium. Journal of Social Issues 61: 641-63. [CrossRef]

Snyder, C. R. 2000. Hypothesis: There is hope. In Handbook of Hope. Edited by C. R. Snyder. San Diego: Academic Press, pp. 3-21.

Stavrova, Olga, Detlef Fetchenhauer, and Thomas Schlösser. 2013. Why are religious people happy? The effect of the social norm of religiosity across countries. Social Science Research 42: 90-105. [CrossRef]

Steger, Michael F., and Patricia Frazier. 2005. Meaning in Life: One Link in the Chain from Religiousness to Well-Being. Journal of Counseling Psychology 52: 574-82. [CrossRef]

Stephenson, Charlotte. 1991. The concept of hope revisited for nursing. Journal of Advanced Nursing 16: 1456-61. [CrossRef] [PubMed]

Teigen, Karl Halvor. 1997. Luck, envy and gratitude: It could have been different. Scandinavian Journal of Psychology 38: 313-23. [CrossRef]

Tsang, Joo-Ann, Schulwitz Ashleigh, and Robert D. Carlisle. 2012. An experimental test of the relationship between religion and gratitude. Psychology of Religion and Spirituality 4: 40-55. [CrossRef]

Tsang, Jo-Ann, Michael E. McCullough, and William T. Hoyt. 2005. Psychometric and rationalization accounts of the religionforgiveness discrepancy. Journal of Social Issues 61: 785-805. [CrossRef]

Tsang, Jo-Ann, Robert D. Carlisle, and Rosemary L. Al-Kire. 2020. Forgive and remember: The relationship between religion and the recollection of transgressions. The International Journal for the Psychology of Religion 30: 35-47. [CrossRef]

van Oudenhoven, Jan Pieter, Boele de Raad, Carmen Carmona, Anne-Kathrin Helbig, and Meta van der Linden. 2012. Are virtues shaped by national cultures or religions? Swiss Journal of Psychology 71: 29-34. [CrossRef]

Vilchinsky, Noa, and Shlomo Kravetz. 2005. How are religious belief and behavior good for you? An investigation of mediators relating religion to mental health in a sample of israeli jewish students. Journal for the Scientific Study of Religion 44: 459-71. [CrossRef]

Watkins, Philip C., Kathrane Woodward, Tamara Stone, and Russell L. Kolts. 2003. Gratitude and happiness: Development of a measure of gratitude, and relationships with subjective well-being. Social Behavior and Personality 31: 431. [CrossRef]

Wnuk, Marcin, and Jerzy Tadeusz Marcinkowski. 2014. Do existential variables mediate between religious-spiritual facets of functionality and psychological wellbeing. Journal of Religion and Health 53: 56-67. [CrossRef] [PubMed]

Wnuk, Marcin. 2017. A Psychometric Evaluation of the Santa Clara Strength of Religious Faith Questionnaire among Students from Poland and Chile. Pastoral Psychology 66: 551-62. [CrossRef] [PubMed]

Wnuk, Marcin. 2020. Psychometric Evaluation of the Gratitude Toward the Organization Scale. Central European Management Journal 28: 149-67. [CrossRef]

Zarzycka, Beata, Jacek Šliwak, Dariusz Krok, and Paweł Ciszek. 2019. Religious comfort and anxiety in women with cancer: The mediating role of hope and moderating role of religious struggle. Psycho-Oncology 28: 1829-35. [CrossRef] 